\title{
Incidence of sexually transmitted diseases in rape victims during 1984
}

\author{
G E FORSTER, J PRITCHARD, P E MUNDAY, AND D GOLDMEIER
}

From the Praed Street Clinic, St Mary's Hospital, London, and the Division of Sexually Transmitted Diseases, Medical Research Council Clinical Research Centre, Harrow, Middlesex

SUMMARY During 1984, 46 women attended the sexually transmitted disease (STD) clinic at St Mary's Hospital alleging that they had been raped. At presentation, 31 (67\%) were asymptomatic. Evidence of STD was found in $14(30 \%)$ women, mixed infections occurring in four. Chlamydia trachomatis and Trichomonas vaginalis were each detected in six (13\%) patients and Neisseria gonorrhoeae in three (6\%). The source of the infection could not confidently be traced to the alleged rapist. Two patients were found to have cervical cytological abnormalities suggestive of cervical intraepithelial neoplasia of grades II or III. One woman became pregnant as a consequence of the sexual assault.

Investigations may unveil infection or other abnormalities, which are incidental to the rape but nevertheless require further investigation and treatment.

\section{Introduction}

The incidence of rape, defined as the act or crime of having sexual intercourse with a woman without her consent, either by using force or by fraudulent means, is not known. ${ }^{1}$ Many cases are not reported. ${ }^{2-4}$ The risk of acquiring a sexually transmitted disease (STD) after such an attack is not known.

Earlier studies have dealt almost exclusively with the risk of acquiring gonorrhoea and syphilis. ${ }^{5}$ In North America, Neisseria gonorrhoeae was found at presentation in $2.5 \%$ to $13 \%$ of all sexual assault victims and subsequently confirmed by culture, but serological evidence of syphilis was present in less than $1 \% .^{5}$ In Washington DC the risk of acquiring gonorrhoea after rape was estimated at $5 \cdot 8 \%$, but more than half of the infections were detected at a second or subsequent examination. The number of cases of syphilis detected was unaffected by length of follow up. ${ }^{6}$

There are few data on the risk of acquiring one of the

Address for reprints: Dr J Pritchard, Praed Street Clinic, St Mary's Hospital, Praed Street, London W2 1NY

Accepted for publication 18 November 1985 newly recognised sexually transmitted microorganisms, such as Chlamydia trachomatis, as a result of rape. In Seattle, Trichomonas vaginalis was apparently transmitted more often than $N$ gonorrhoeae. ${ }^{5}$

We have assessed the inciaence of STD and associated conditions in rape victims who attended the STD clinic of St Mary's Hospital in 1984.

\section{Patients and methods}

All women who attended the Praed Street Clinic in 1984 alleging that they had been raped, were investigated according to standard clinic procedure (Praed Street Clinic Handbook, 1984). A full account of the assault was obtained only if it was volunteered by the woman. Details of contraceptive practice and the menstrual cycle were documented, and the site(s) of possible infection were recorded.

Material obtained from the urethra and endocervix was stained with Gram's reagent and examined for polymorphonuclear leucocytes and Gram negative intracellular diplococci. Specimens were obtained from the urethra, endocervix, rectum, and throat, as appropriate, for culture for $\boldsymbol{N}$ gonorrhoeae. Endocervical and urethral specimens were taken for identifica- 
tion of $C$ trachomatis either directly using a fluorescein labelled monoclonal antibody (MicroTrak, Syva, Maidenhead, Berkshire, England) ${ }^{7}$ or by isolating the micro-organism in cycloheximide treated McCoy cells. ${ }^{8} T$ vaginalis, "clue" cells, and monilia hyphae were sought by direct microscopy of secretions from the posterior vaginal fornix after they had been mixed with saline. Herpes simplex virus was sought only when there was a clinical suspicion of this infection. Cervical cytology was performed in those women who had not had a recent Papanicolaou stained (Pap) smear. A bimanual pelvic examination was undertaken. Serological tests for syphilis were carried out at the initial assessment.

Patients were advised to return for reassessment after 14 days when further investigations were carried out if appropriate. A third visit was recommended six to eight weeks after the incident so that serological tests for syphilis could be repeated. Treatment was given for diagnosed infections according to standard clinic practice (Praed Street Clinic Handbook, 1984).

\section{Results}

\section{EPIDEMIOLOGY}

Forty six women (mean age 25, range 13-40, years) attended during 1984 alleging that they had been raped. The mean time from the assault to presentation was 25 days (range one day to one year), and 27 (59\%) patients presented within 10 days of the incident. Thirteen women had been referred formally or informally for examination by other agencies, including the police and general practitioners.

The rape had been reported to the police by 16 (35\%) women, and the assailant was known to the victim in $13(28 \%)$ cases. In seven (15\%) incidents, two or three assailants were involved. Oral contact had taken place before the rape in six cases and anal contact in two. Twenty eight (60\%) women had a regular sexual partner, but four had not informed their regular sexual partners of the incident when they first attended. A 13 year old girl had had no prior sexual experience.

\section{STD AND OTHER INFECTIONS}

Fifteen patients presented with symptoms including vaginal discharge, pruritus, and depression, but there was no correlation between the presence of symptoms and the detection of STD.

Fourteen (30\%) women had evidence of STD, four of whom had more than one infection. Nine of this group presented within 10 days of the incident. $C$ trachomatis and $T$ vaginalis were the commonest micro-organisms detected, each being present in six patients. $N$ gonorrhoeae was isolated in three cases
TABLE Incidence of sexually transmitted diseases, bacterial vaginosis, and candidosis in 46 rape victims

\begin{tabular}{lc}
\hline $\begin{array}{l}\text { Micro-organism isolated } \\
\text { or condition detected }\end{array}$ & No of patients* \\
\hline Neisseria gonorrhoeae & 3 \\
Chlamydia trachomatis & 6 \\
Trichomonas vaginalis & 6 \\
Pediculosis pubis & 2 \\
Scabies & 1 \\
Condylomata acuminata & 1 \\
Bacterial vaginosis & 7 \\
Candidosis & 3 \\
\hline
\end{tabular}

* Includes four patients with mixed infections.

(table). In five women, STD was not found until the second attendance, eight to 35 days later. Two of these women had chlamydial infections, two had $T$ vaginalis infection, and one had scabies, which developed after an initial gonococcal infection had been treated. A clinical diagnosis of pelvic inflammatory disease was made in one of the women with chlamydial infection, who also had a history of salpingitis.

Bacterial vaginosis and candidosis were diagnosed in 10 patients. Only one woman had used antibiotics within one month before her clinic attendance.

\section{CERVICAL CYTOLOGY}

Cervical smears from 22 of the 46 women were examined cytologically, and six showed abnormal results. Two of the smears had evidence of a bacterial exudate, two inflammatory atypia, and two changes suggestive of cervical intraepithelial neoplasia (CIN) of grades II or III. The two patients with CIN underwent colposcopy and subsequent laser treatment.

\section{CONTRACEPTION AND OUTCOME OF PREGNANCY}

At the time of the rape $18(39 \%)$ women were using adequate contraception (oral contraception or an intrauterine contraceptive device (IUCD)) or had been sterilised. Postcoital hormonal contraception had been prescribed for five patients before their clinic attendance. Postcoital contraception (IUCD insertion) was offered to one patient who presented 72 hours after the incident, but the offer was declined. The pregnancy that resulted was subsequently terminated.

\section{FOLLOW UP}

Twenty seven (59\%) patients attended for follow up two to $\mathbf{4 8}$ days later. Two women were moving away from London and were advised of alternative follow up arrangements. Three women declined follow up and after discussion received results by post. 


\section{Discussion}

During $1984,14(30 \%)$ of 46 rape victims attending the Praed Street Clinic were infected with a sexually transmitted micro-organism. In five women, the infection would not have been detected by a single examination. Only one patient had been using antibiotics. The failure to detect infection in 31 patients could not therefore be attributed to the use of antibiotics. $C$ trachomatis and $T$ vaginalis were the commonest micro-organisms detected, each being present in six patients. The source of the infection, however, could not confidently be traced by our current investigations to the alleged rapist, and could have reflected pre-existing pathology in some cases.

The results of this study do not support the need for prophylactic antibiotic treatment, as the choice of antibiotic would be difficult. If prophylaxis were thought to be necessary a regimen suitable to treat incubating syphilitic, gonococcal, chlamydial, trichomonal, and herpetic infections would be necessary. Such treatment may not be acceptable to all rape patients.

Comprehensive investigations of alleged rape victims may well unveil infections or abnormalities incidental to the rape, but nevertheless requiring treatment. Six women were found to have abnormal Pap smears, two patients required laser treatment. Other workers have found an increased prevalence of abnormal Pap smears in rape victims. ${ }^{9}$

The probability that a pregnancy will occur after rape is thought to be about 1 in 100 sexual assaults of women of reproductive age. ${ }^{5}$ Between $1 \%$ and $3 \%$ of women became pregnant as a result of sexual assault when followed up in Washington DC. ${ }^{6}{ }^{10}$ No pregnancies resulted after rape when postcoital contraception was offered at the initial examination. ${ }^{11-13}$ Eighteen (39\%) of the 46 women in our study were adequately protected against pregnancy. Five patients had already received postcoital hormonal contraception before their clinic attendance, and none became pregnant. One pregnancy occurred in a woman who would have required postcoital IUCD insertion because of the timing of her attendance after the rape. We believe that postcoital contraception should be offered to those women at risk of pregnancy after rape, if the timing is appropriate.

Long term effects on the physical and psychological health of the woman are difficult to assess. The need for a service in Britain providing strictly confidential and appropriate care for the physical, emotional, and social needs of rape victims has been debated. ${ }^{314}$ Neither examination suites within police stations nor departments of genitourinary medicine seem appropriate settings for this service. Sexual assault centres fulfilling these needs have been established in Australia $^{3}$ and the United States of America, ${ }^{15}$ the latter being run by paramedical staff in some cities.

We thank Dr B J Thomas and Mrs J Carder from the Division of Sexually Transmitted Diseases, MRC Clinical Research Centre, Harrow, Middlesex, for the provision of a chlamydial diagnostic service.

\section{References}

1. Hawkins JM, ed. The Oxford paperback dictionary. 1st ed. London: Oxford University Press. 1982;529.

2. Chanteau D. Rape: women want self-defence weapons. The Standard 1985 January 10:13

3. Duddle $\mathbf{M}$. The need for sexual assault centres in the United Kingdom. Br Med J 1985;290:771-3.

4. Anonymous. Rapist and victim: some facts. Newsweek 1985 May 20, No. 20: 27.

5. Cate W, Blackmore CA. Sexual assault and sexually transmitted diseases. In: Holmes KK, Mårdh P-A, Sparling PF, Wiesner PJ, eds. Sexually transmitted diseases. New York: McGraw-Hill Book Company, 1984:119-125.

6. Hayman CR, Lanz C, Fuentes R, Algo K. Rape in the District of Columbia. Am J Obstet Gynecol 1972;113:91-7.

7. Thomas BJ, Evans RT, Hawkins DA, Taylor-Robinson D. Sensitivity of detecting Chlamydia trachomatis elementary bodies in smears by use of a tluorescein labelled monoclonal antibody: comparison with conventional chlamydial isolation. J Clin Pathol 1984;37:81 2-6.

8. Evans RT, Woodland RM. Detection of chlamydiae by isolation and direct examination. Br Med Bull 1983;39:181-6.

9. Seltzer VL, Hassman H, Bigelow B. Abnormal Papanicolaou smears found in victims of sexual assault. $J$ Reprod Med 1978;20:233.

10. Hayman CR, Lanza C. Sexual assault on women and girls. Am J Obstet Gynecol 1971;109:480-6.

11. Kaufman A, Vandermeer J, DiVasto P, et al. Follow-up of rape victims in a family practice setting. South Med J 1976; 69: 1569 .

12. Soules MR, Stewart SK, Brown KM, Pollard AA. The spectrum of alleged rape. J Reprod Med 1978;20:33-9.

13. Evrard JR, Gold EM. Epidemiology and management of sexual assault victims. Obstet Gynecol 1979;53:381-7.

14. Roberts R. The need for sexual assault centres in the UK. Br Med J 1985;290:934-5.

15. Solola A, Scott C, Severs H, Howell J. Rape: management in a noninstitutional setting. Obstet Gynecol 1983;61:373-8. 